\title{
Gestão responsável: responsabilidade, ética e sustentabilidade a partir do Principles for Responsible Management Education (PRME)
}

Responsible management: responsibility, ethics, and sustainability from the Principles for Responsible Management Education (PRME)

Gestión responsable: responsabilidad, ética y sostenibilidad a partir de los Principios para la Educación en Gestión Responsable (PRME)

Flavio Hourneaux Junior

- Professor doutor do Departamento de Administração da Faculdade de Economia, Administração e Contabilidade da Universidade de São Paulo (FEA-USP)

- $\quad$ Representante da FEA-USP no Principles for Responsible Management Education (PRME) da Organização das Nações Unidas (ONU)

- Coordenador científico do Encontro Internacional sobre Gestão Empresarial e Meio Ambiente (Engema)

- $\quad$ Co-editor da Revista de Administração da USP (Rausp)

- E-mail: flaviohjr@usp.br

Adriana Cristina Ferreira Caldana

- Doutora em Psicologia pela Universidade de São Paulo (USP)

- Professora de Recursos Humanos e Sustentabilidade na Faculdade de Economia, Administração e Contabilidade de Ribeirão Preto (FEA-RP) da USP

- $\quad$ Líder do grupo de pesquisa Global Organizational Learning and Development Network (Golden) for Sustainability no Brasil

- Coordenadora do Escritório de Sustentabilidade da FEA-RP/USP, criado para a promoção do Principles for Responsible Management Education (PRME) da Organização das Nações Unidas (ONU)

- E-mail: caldana@usp.br 


\section{Resumo}

O ensaio apresenta os principais elementos e diretrizes da chamada gestão responsável (GR): responsabilidade, ética e sustentabilidade. São descritos também os principais elementos que constituem o Principles for Responsible Management Education (PRME), iniciativa da Organização das Nações Unidas (ONU) para o fomento e desenvolvimento da GR. Além disso, os autores relatam as experiências do PRME no Brasil e no mundo e, principalmente, os resultados do congresso realizado no Brasil, em setembro de 2017, no qual se discutiu o tema em diversas perspectivas.

\section{PALAVRAS-CHAVE: GESTÃORESPONSÁVEL • RESPONSABILIDADE •ÉTICA •SUSTENTABILIDADE • PRINCIPLES FOR RESPONSIBLE MANAGEMENT EDUCATION (PRME)}

\section{Abstract}

This essay presents the main elements and guidelines of the so-called responsible management (RM): responsibility, ethics and sustainability. They describe the main elements that form the Principles for Responsible Management Education (PRME), an United Nations (UN) initiative for the RM promotion and development. In addition, the authors report on PRME's experiences in Brazil and in the world, especially the results of the conference held in Brazil, in September 2017, where the subject was discussed through different perspectives.

KEYWORDS: RESPONSIBLE MANAGEMENT • RESPONSIBILITY • ETHICS • SUSTAINABILITY • PRINCIPLES FOR RESPONSIBLE MANAGEMENT EDUCATION (PRME)

\section{Resumen}

El ensayo presenta los principales elementos y directrices de la llamada gestión responsable (GR): responsabilidad, ética y sostenibilidad. Se describen también los principales elementos que constituyen el Principles for Responsible Management Education (PRME), iniciativa de la Organización de las Naciones Unidas (ONU) para el fomento y desarrollo de la GR. Además, los autores relatan las experiencias del PRME en Brasil y en el mundo y, principalmente, los resultados del congreso realizado en Brasil, en el septiembre del 2017, donde se discutió el tema en sus diferentes perspectivas.

PALABRAS CLAVE: GESTIÓN RESPONSABLE • RESPONSABILIDAD • ÉTICA • SOSTENIBILIDAD • PRINCIPLES FOR RESPONSIBLE MANAGEMENT EDUCATION (PRME) 
$\mathrm{E}$

m níveis global, nacional e local, as discussões em torno do desenvolvimento sustentável e da sustentabilidade cada vez mais se propagam e se legitimam nas diferentes esferas da sociedade. Nesse sentido, discute-se como enfoque deste artigo a formação dos profissionais que trabalham ou trabalharão nas organizações para que eles estejam aptos a colocar aspectos de cunho social, ambiental, político, territorial e cultural, em uma mesma hierarquia de valor e importância, da mesma forma que os aspectos econômicos são tradicionalmente tratados (Brunstein; Godoy; Silva, 2014). Assim, é preciso considerar que a responsabilidade sobre o desenvolvimento sustentável permeia não somente aspectos econômicos e privados, mas interesses que passam a moldar o perfil de formação acadêmica das novas gerações (Barth et al., 2007).

As instituições de ensino superior (IES) recebem destaque como elementos fundamentais nesse processo pois, além de desempenharem importante papel no processo de produção e disseminação de conhecimento, são capazes de propiciar tanto a aprendizagem formal quanto a informal, necessárias para a formação de pessoas qualificadas. 0 envolvimento das IES em relação ao desenvolvimento sustentável (DS) não é recente. Desde o final da década de 1980, são realizadas conferências e firmados acordos que evidenciam, afirmam e reafirmam o compromisso das universidades com o DS (Jacobi; Raufflet; Arruda, 2011; Leal Filho, 2011; Lozano-García; Kevany; Huisingh, 2006).

Nesse contexto, entre outras iniciativas, surge o Principles for Responsible Management Education (PRME), criado em 2007, a partir de uma iniciativa da Organização das Nações Unidas (ONU), como um complemento ao Pacto Global (Global Compact), para desenvolvimento da Gestão Responsável (GR) nas IES em todo o mundo. Entre suas diversas iniciativas em todos os seus capítulos no mundo, o PRME realiza anualmente uma conferência global para discussão e disseminação do que tem sido feito no mundo a respeito dos seus temas, a Responsible Management Education (RME) Research Conference.

Assim, o objetivo deste artigo pode ser dividido em três partes: (a) apresentar os principais elementos e diretrizes da GR (responsabilidade, ética e sustentabilidade); (b) descrever os principais elementos que constituem o PRME e as experiências no Brasil e no mundo; (c) relatar os resultados da $4^{\text {th }}$ RME Research Conference, realizada no Brasil em setembro de 2017 , que discutiu o tema em diversas perspectivas.

\section{CONTEXTO E ELEMENTOS DA GR}

Os governos estão progressivamente criando legislações formais que institucionalizam os assuntos de negócios responsáveis em nível nacional. Organizações internacionais, como a Pacto Global, das Nações Unidas, e o Conselho Empresarial Mundial para o Desenvolvimento Sustentável (WBCSD), têm estabelecido redes de negócio responsáveis. Normas, como a ISO 26000 (responsabilidade social) e a ISO 14000 (gestão ambiental), fornecem orientações para implementação e, frequentemente, certificação, ou servem como rankings. Muitos mercados de ações também lançaram índices de sustentabilidade em larga escala, por exemplo: o índice britânico FTSE4Good; o índice norte-americano Dow Jones de sustentabilidade; o índice chinês Hang Seng de sustentabilidade empresarial; o índice de sustentabilidade empresarial ISE-Bovespa.

Em 2015, na Conferência da ONU, realizada em Nova York, a importância do DS global foi mais uma vez ratificada, pelos 193 Estados-membros e pelo alto comissariado da ONU, levando ao lançamento dos objetivos de desenvolvimento sustentável (ODS), como parte da chamada Agenda 2030, proposta como "um plano de ação para as pessoas, para o planeta e para a prosperidade" (United Nations, 2015). Os ODS substituem os objetivos do milênio (ODM), num esforço de continuidade progressiva, utilizando-se de base e indo além, para consolidar-se nos propósitos da Agenda 2030 num período de 15 anos. Ao todo, equivalem a 17 objetivos com 169 metas específicas que, trabalhadas de maneira integrada, têm potencial para promover a implantação efetiva, em nível global, do DS em suas três dimensões: econômica, social e ambiental (United Nations, 2015). 
Assim, o contexto em que se inserem as organizações demanda uma mudança na forma como estas devem ser gerenciadas. A partir disso, surge a GR, que se contrapõe ao que poderia ser a denominada "gestão tradicional". Enquanto o "paradigma da gestão tradicional" teria características como a busca da maximização do lucro, o crescimento (receitas, mercado e consumo) como premissa do negócio, o foco no curto prazo e nos aspectos econômicos e a priorização dos interesses dos acionistas. No "paradigma da GR", prevaleceriam a busca por otimização do lucro - ao contemplar os interesses dos diferentes stakeholders organizacionais -, o objetivo de um volume ótimo (crescer, manter ou encolher o negócio), a identificação dos impactos do negócio no longo prazo e um balanceamento entre os aspectos econômicos, sociais e ambientais (triple bottom line) do negócio (Laasch; Conaway, 2015). Dessa forma, como descrito no Quadro 1, a GR seria baseada em três esferas: sustentabilidade, responsabilidade e ética.

Quadro 1: Esferas da GR.

\begin{tabular}{|c|c|}
\hline Esfera & Descrição \\
\hline Sustentabilidade & $\begin{array}{l}\text { Geralmente está relacionada às questões sociais, ambientais } \\
\text { e econômicas que ameaçam o bem-estar ou até mesmo a } \\
\text { sobrevivência das gerações atuais e futuras. Por exemplo, tais } \\
\text { questões sistêmicas incluem o aquecimento global, que em } \\
\text { um nível empresarial é traduzido como o gerenciamento de } \\
\text { gás carbônico }\left(\mathrm{CO}_{2}\right) \text {, a crise global da água, a degradação dos } \\
\text { ecossistemas importantes para a sobrevivência e o excesso de } \\
\text { população do planeta. Em nível empresarial, essas questões } \\
\text { são frequentemente traduzidas como TBL, englobando os } \\
\text { desempenhos nas dimensões social, ambiental e econômica. }\end{array}$ \\
\hline Responsabilidade & $\begin{array}{l}\text { Tem como função crucial a relação com os vários grupos } \\
\text { que afetam ou são afetados por um empreendimento, os } \\
\text { stakeholders, ou partes interessadas. Por exemplo, a área de } \\
\text { normas trabalhistas está preocupada com o relacionamento } \\
\text { com os funcionários, a dos direitos do consumidor aos } \\
\text { consumidores e a de práticas de logística integrada aos } \\
\text { fornecedores. Cada um é um importante grupo de stakeholders. }\end{array}$ \\
\hline Ética & $\begin{array}{l}\text { Relaciona-se à tomada da decisão certa em situações } \\
\text { em que existe um dilema e refere-se a correntes de } \\
\text { filosofia moral. Assim, por exemplo, o tema sobre direitos } \\
\text { humanos e naturais está altamente relacionado à filosofia } \\
\text { da ética dos direitos e justiça. A governança corporativa } \\
\text { gira em torno de dilemas, como o dilema do principal- } \\
\text { agente, ou quais interesses devem ser protegidos (se } \\
\text { os do proprietário ou dos gestores da empresa). }\end{array}$ \\
\hline
\end{tabular}

Fonte: Laasch e Conaway (2015).

Assim, cada uma dessas três esferas - e suas inter-relações - seria uma base para a GR e para a construção e disseminação do conhecimento a que ela se refere. A quantidade de temas e a interdisciplinaridade presentes geram inúmeras possibilidades de atuação que são alternativas - e complementares - à gestão tradicional, como se observa no Quadro 2. 
Quadro 2: Temas da GR estruturados pelos campos de interesse.

\begin{tabular}{|l|l|l|}
\hline \multicolumn{1}{|c|}{$\begin{array}{c}\text { Sustentabilidade } \\
\text { (TBL) }\end{array}$} & Responsabilidade (stakeholders) & \multicolumn{1}{c|}{$\begin{array}{c}\text { Ética } \\
\text { (dilema moral) }\end{array}$} \\
\hline Crises globais da água e dos oceanos & Normas trabalhistas & Direitos humanos e naturais \\
\hline Aquecimento global & Proteção dos direitos ao consumidor & Desigualdade de renda \\
\hline $\begin{array}{l}\text { Desmatamento e perda de } \\
\text { nutrientes do solo }\end{array}$ & Diversidade no local de trabalho & Governança corporativa \\
\hline Excesso de população & Bem-estar da comunidade & Concorrência leal \\
\hline Pobreza e fome & Práticas integradas de supply chain & Corrupção \\
\hline Degradação dos ecossistemas & Boa cidadania & Ética empresarial \\
\hline Perdas da biodiversidade & Respeito às leis & Contabilidade ética \\
\hline
\end{tabular}

Fonte: Laasch e Conaway (2015).

Como mostrado no Quadro 2, é grande a diversidade e complexidade dos temas tratados pela GR. No entanto, em função das mudanças no contexto organizacional, a inclusão desses temas se torna cada mais premente, desde a sua introdução na estratégia das organizações (Bonn; Fischer, 2011; Stead; Stead, 2008) até a comunicação e o reporte das ações das organizações e seus impactos para os stakeholders (Schaltegger; Wagner, 2006), muitas vezes realizada ainda de forma não apropriada (Baumgartner; Ebner, 2010).

\section{A EDUCAÇÃO E A FORMAÇÃO DA GR}

Em 2005, a Organização das Nações Unidas para a Educação, a Ciência e a Cultura (Unesco) lançou a iniciativa Década da Educação para o Desenvolvimento Sustentável (DEDS), cujo objetivo era "integrar os valores inerentes ao DS em todos os aspectos da aprendizagem com o intuito de fomentar mudanças de comportamento que permitam criar uma sociedade sustentável e mais justa para todos" (Organização das Nações Unidas para a Educação, a Ciência e a Cultura, 2005, p. 16).

Assim, a DEDS seria a linha mestra para a consolidação do DS no ensino, baseando-se e reforçando-se os pontos definidos na Agenda 21, enfatizando a educação como um fator vital para a promoção do DS, com o propósito de influenciar e fomentar uma mudança na estrutura curricular, por meio da introdução da sustentabilidade (Gadotti, 2009). Mais do que uma alternativa para definitivamente solucionar todos os problemas da crise ecológica, a educação para a sustentabilidade deve ser vista como uma abordagem de aprendizado que propicia a capacidade de cooperar diante de incertezas inerentes à complexidade global que enfrenta desafios não precedentes (Jones; Trier; Richards, 2008).

De acordo com os estudos realizados por Jabbour et al. (2013), como principais resultados da DEDS, é razoável constatar que a incorporação de questões associadas à sustentabilidade inicia-se com a pesquisa e com o ensino, de modo dependente à motivação pessoal de poucos professores. Ademais, paradoxalmente, ser líder no ensino superior não significa ter uma posição de liderança no ensino de sustentabilidade. Com frequência, universidades com tais características sofrem resistências internas para agregar mudanças como essa. De maneira geral, o que se nota é que, apesar da diversidade de iniciativas e abordagens, internacional e nacionalmente, a consolidação da inserção do DS segue como sendo um desafio para as IES que, apesar de já terem iniciado a inserção do tema em suas matrizes curriculares, muitas vezes ainda o fazem de forma pontual e não integrada. 


\section{OPRME}

O PRME foi criado em 2007 a partir de uma iniciativa da ONU. Seu objetivo é desenvolver uma plataforma de engajamento global para instituições de ensino que seja baseada nos princípios do Pacto Global da ONU (History..., 2017). Assim, o PRME segue seis princípios básicos, que devem orientar a atuação das IES signatárias:

Quadro 3: Os seis princípios do PRME.

\begin{tabular}{|c|c|}
\hline Princípio & Definição \\
\hline Propósito & $\begin{array}{l}\text { Desenvolver as capacidades dos alunos para serem } \\
\text { futuros geradores de valor sustentável para as } \\
\text { empresas e a sociedade em geral e trabalhar para } \\
\text { uma economia global inclusiva e sustentável. }\end{array}$ \\
\hline Valores & $\begin{array}{l}\text { Incorporar em atividades acadêmicas e } \\
\text { currículos os valores da responsabilidade } \\
\text { social global como retratado em iniciativas } \\
\text { internacionais, como o Pacto Global da ONU. }\end{array}$ \\
\hline Metodologia & $\begin{array}{l}\text { Criar estruturas de ensino, materiais, } \\
\text { processos e ambientes que possibilitem } \\
\text { experiências de aprendizagem eficazes } \\
\text { para a liderança responsável'. }\end{array}$ \\
\hline Pesquisa & $\begin{array}{l}\text { Participar de pesquisas conceituais e empíricas } \\
\text { para o avanço da compreensão sobre o papel, } \\
\text { como também para a dinâmica e o impacto } \\
\text { das corporações na criação de valor social, } \\
\text { ambiental e econômico sustentável. }\end{array}$ \\
\hline Parcerias & $\begin{array}{l}\text { Interagir com os gestores das corporações } \\
\text { de negócios para ampliar o conhecimento } \\
\text { sobre seus desafios no cumprimento de } \\
\text { responsabilidades sociais e ambientais } \\
\text { e explorar abordagens conjuntamente } \\
\text { eficazes para enfrentar esses desafios. }\end{array}$ \\
\hline Diálogo & $\begin{array}{l}\text { Facilitar o diálogo e apoiar o debate entre } \\
\text { educadores, estudantes, empresas, governos, } \\
\text { consumidores, mídia, organizações da sociedade } \\
\text { civil e outros grupos interessados sobre questões } \\
\text { críticas relacionadas à responsabilidade } \\
\text { social global e sustentabilidade. }\end{array}$ \\
\hline
\end{tabular}

Fonte: PRME Chapter Brazil (2015a, 2015b, 2015c, 2015d, 2015e, 2015f).

1 Liderança responsável é um conceito-chave no âmbito do PRME que, segundo Minuzzi, Filho e

Santos (2009), refere-se a um exercício de liderança em que há clareza quanto aos valores assumidos, considerações morais quanto ao exercício do poder, concepções sobre justiça e julgamentos éticos. 
Atualmente, há mais de 650 escolas associadas ao PRME em todo o mundo, sendo que no Brasil ao todo são 32 escolas signatárias. Após tornar-se signatário do PRME, a instituição de ensino deve organizar-se para que os valores pautados por essa plataforma façam parte das operações da organização em seus currículos e pesquisas, bem como sirvam como base para as ações da instituição (PRME Chapter Brazil, 2017; History..., 2017).

O PRME busca integrar cada vez mais os ODS nos seus campos de trabalho e consequentemente na pesquisa científica. Tal movimento é promissor, na medida em que estimula o olhar acadêmico a se voltar para questões iminentes do desenvolvimento humano, sob o prisma multidimensional dos ODS e de suas 169 metas (United Nations, 2015). A ambição e complexidade de tal tarefa suscita questões, teóricas e aplicadas, que precisam ser abordadas em esforços conjuntos e transdisciplinares e que foram o foco central da $4^{\text {th }}$ RME Research Conference, realizada em Curitiba em setembro de 2017, cujos objetivos e características serão apresentados adiante.

\section{APRESENTAÇÃO: PANORAMA E FORMATO DA CONFERÊNCIA}

Num exercício contínuo de discussão acadêmica, vários stakeholders foram convidados pelo PRME Global, pelo Programa das Nações Unidas para o Desenvolvimento no Brasil (PNUD) e pelo Comitê Brasileiro do Pacto Global (CBPG) a se reunirem em torno dos desafios da Agenda 2030 na $4^{\text {th }}$ RME Research Conference. Participaram representantes de universidades e instituições de ensino - públicas e privadas - do Brasil e do exterior, como também do setor governamental, do terceiro setor brasileiro, das próprias organizações fomentadoras nacionais e internacionais do evento, além dos congressistas e pesquisadores em temas relacionados à formação com base na GR. ${ }^{1}$

O tema central da conferência foi "Novas questões de pesquisa para o avanço da implementação dos objetivos do desenvolvimento sustentável" alinhado aos desafios e perspectivas do movimento da Agenda 2030, tais questões, teóricas e práticas, buscavam contribuir com os seguintes objetivos específicos: melhorar a compreensão da complexidade, interconexão e natureza multidimensional dos 17 ODS e os respectivos 169 alvos, com o objetivo geral de fomentar mais pesquisas relacionadas aos diversos temas da Agenda 2030; criar soluções práticas (negócios, gerenciamento educacional e metodologia, elaboração de políticas, estratégias escolares, administração governamental e outras) que possam ser aplicadas local, nacional e globalmente; estabelecer um terreno comum para as empresas, educação gerencial (pesquisadores, professores e gerentes de escolas), formuladores de políticas, governo, organização não governamental (ONG), jovens, mídia, editores, organizações internacionais, associações, redes e outras partes interessadas para criar e aprimorar as parcerias já existentes por meio do diálogo direto entre esses stakeholders.

A elaboração do programa da conferência visou uma coerência geral, dentro dos principais tópicos pretendidos, bem como a abertura para propostas inovadoras, fomentando a participação ativa da comunidade PRME, da comunidade de pesquisa em geral e dos demais stakeholders de diferentes partes do mundo. 0 evento contemplou a participação de proeminentes atores no contexto da articulação da Agenda 2030, trazendo vozes da educação responsável em gestão, do meio empresarial, dos pesquisadores, do governo e dos alunos, entre os quais se destacam os conferencistas Jeffrey Sachs, Maurizio Zollo e Isabel Rimanoczy.

1 A 4th RME Research Conference foi realizada pela primeira vez no hemisfério sul, sendo organizada pelo capítulo brasileiro do PRME, pela Universidade de São Paulo (por meio da parceria entre as unidades FEA-USP e FEA-RP/USP), pela Federação das Indústrias do Paraná (Fiep), pela Fundação Instituto de Pesquisas (FIA) e pelo capítulo de países de língua germânica do PRME (PRME DACH), em Curitiba, em 13 e 14 de setembro de 2017. 
Jeffrey Sachs, da Universidade Columbia, Estado Unidos, e special advisor do secretário geral da ONU, é um dos principais influenciadores globais de DS e suas pesquisas serviram de base para a definição tanto dos ODM quanto dos ODS. Maurizio Zollo, da Università Bocconi, Itália, é coordenador do Golden for Sustainability, uma parceria global entre empresas e universidades dos vários continentes do planeta, para criação de modelos de gestão sustentável para as empresas. Isabel Rimanoczy, da Nova Southeastern University Florida, Estados Unidos, é coordenadora do grupo de Sustainability Mindset do PRME e é embaixadora da iniciativa global AIM2Flourish que visa promover, educar e dar visibilidade a inovadoras iniciativas de negócios e empreendedores ligados aos ODS.

Seguindo uma política de abertura à participação de todas as partes interessadas, o comitê organizador da $4^{\text {th }}$ RME Research Conference abriu um período para a submissão de áreas temáticas (tracks). Entretanto, após o encerramento do prazo, percebeu-se que várias propostas eram apenas artigos a serem submetidos, então optou-se por formar seis áreas temáticas que acomodassem todos os stakeholders do PRME. 0 Quadro 4 apresenta os tracks que foram formados.

Quadro 4: $4^{\text {th }}$ RME Research Conference - Tracks.

\begin{tabular}{|l|l|}
\hline \multicolumn{1}{|c|}{ Princípio } & \multicolumn{1}{c|}{ Definição } \\
\hline ODS e Educação & $\begin{array}{l}\text { O objetivo foi discutir os ODS e sua relação e/ } \\
\text { ou aplicação em educação em todos os seus } \\
\text { níveis. Este track teve três sessões paralelas. }\end{array}$ \\
\hline ODS e Pesquisa Científica & $\begin{array}{l}\text { O objetivo foi discutir como os ODS são ou podem } \\
\text { ser considerados para fins de pesquisa científica. } \\
\text { Este track teve duas sessões paralelas. }\end{array}$ \\
\hline ODS e Negócios & $\begin{array}{l}\text { O objetivo foi discutir como os ODS são ou podem } \\
\text { ser considerados pelas empresas e organizações } \\
\text { em geral. Este trackteve três sessões paralelas. }\end{array}$ \\
\hline ODS e Governo & $\begin{array}{l}\text { O objetivo foi discutir os ODS e seu relacionamento e/ } \\
\text { ou aplicação em políticas públicas e o papel do governo } \\
\text { nesse processo. Este track teve duas sessões paralelas. }\end{array}$ \\
\hline ODS e Sociedade & $\begin{array}{l}\text { O objetivo foi discutir como os ODS estão relacionados } \\
\text { e sendo percebidos pela sociedade, como também } \\
\text { sobre suas consequências, por meio de uma visão } \\
\text { sistêmica. Este trackteve uma sessão paralela. }\end{array}$ \\
\hline Grupos de Trabalho do PRME & $\begin{array}{l}\text { Este trackteve uma sessão sobre anticorrupção, } \\
\text { outra a respeito de alterações climáticas, } \\
\text { mais uma para discutir gênero e, por fim, uma } \\
\text { para discutir a mentalidade sustentável. }\end{array}$ \\
\hline
\end{tabular}

Fonte: Os autores.

Com duração de 1h30min, cada sessão paralela acomodava até seis apresentações orais de 15 min, seguidas por discussões mediadas pelos líderes das áreas temáticas. Ainda ocorreram duas sessões de pôsteres para acomodar uma participação ativa de todos os trabalhos aceitos nos dois dias de programação. Nessas sessões, os pesquisadores tiveram oportunidade de apresentar e debater seu trabalho com todos que circulavam pelo atrium do local. Ao todo, foram 81 apresentações orais de artigos e 28 em formato de pôster. 
Quadro 5: Programação sintética da $4^{\text {th }}$ RME Research Conference.

\begin{tabular}{|c|c|c|}
\hline Tipo da sessão & Atividade & Palestrantes \\
\hline Sessão plenária & $\begin{array}{l}\text { Boas-vindas e plenária } \\
\text { de abertura }\end{array}$ & $\begin{array}{l}\text { Jonas Haertle (PRME Global/EUA) } \\
\text { Cláudio Boechat (GT PRME Antipobreza/Brasil) } \\
\text { José Antonio Fares (CEO Sistema FIEP/Brasil) } \\
\text { Lutz E. Schlange (PRME DACH/Suíça) } \\
\text { Milenko Gudic (GT PRME Antipobreza/Sérvia) } \\
\text { Norman Arruda Filho (PRME Brazil/Brasil) } \\
\text { Jeffrey Sachs (Columbia University/Conselheiro da } \\
\text { ONU para desenvolvimento da Agenda 2030/EUA) }\end{array}$ \\
\hline Mesa-redonda 1 & $\begin{array}{l}\text { "Políticas públicas para } \\
\text { a educação em gestão } \\
\text { responsável e para a pesquisa" }\end{array}$ & $\begin{array}{l}\text { Jonas Haertle (PRME Global/EUA) } \\
\text { Luciana Aguiar (PNUD/Brasil) } \\
\text { Sergio Kelner (Secretário de Governo para a Agenda 2030/Brasil) }\end{array}$ \\
\hline Sessões paralelas 1 & Sessão 1/1 & Educação 1 \\
\hline Sessões paralelas 1 & Sessão 2/1 & Pesquisa 1 \\
\hline Sessões paralelas 1 & Sessão 3/1 & Negócios 1 \\
\hline Sessões paralelas 1 & Sessão 4/1 & Governo 1 \\
\hline Sessões paralelas 1 & Sessão 5/1 & Sociedade 1 \\
\hline Sessões paralelas 1 & Sessão 6/1 & Educação 2 \\
\hline Mesa-redonda 2 & $\begin{array}{l}\text { "Leaders training for } \\
\text { SDGs: companies view" }\end{array}$ & $\begin{array}{l}\text { Christian Hauser (PRME DACH/Suíça) } \\
\text { Pedro Luiz Fernandes (CEO Novozymes/Brasil) } \\
\text { Carlo Linkevieius Pereira (Secretário } \\
\text { Executivo do Pacto Global/Brasil) }\end{array}$ \\
\hline Sessão plenária & Conferência 1 & Maurizio Zollo (Università Bocconi/Itália) \\
\hline Sessões paralelas 2 & Sessão 1//2 & Educação 3 \\
\hline Sessões paralelas 2 & Sessão 2/2 & Pesquisa 2 \\
\hline Sessões paralelas 2 & Sessão 3/2 & Negócios 2 \\
\hline Sessões paralelas 2 & Sessão 4/2 & Negócios 3 \\
\hline Sessões paralelas 2 & Sessão 5/2 & Governo 2 \\
\hline Sessões paralelas 2 & Sessão 6/2 & Workshops 1 \\
\hline Sessão plenária & Conferência 2 & Isabel Rimanoczy (GT PRME Mentalidade Sustentável/EUA) \\
\hline Mesa-redonda 3 & $\begin{array}{l}\text { "ODS na visão dos } \\
\text { acadêmicos" }\end{array}$ & $\begin{array}{l}\text { Al Rosenbloom (Dominican University e GT PRME Anti-pobreza/EUA) } \\
\text { Maria Antônia Brovelli (Politecnico di Milano/Itália) } \\
\text { Consuelo Garcia de la Torre (Tecnologico de Monterrey/México) } \\
\text { Luciana Oranges Cezarino (UFU/Brasil) } \\
\text { Anastasiya Marcheva (GT PRME Anti-pobreza/Bulgária) }\end{array}$ \\
\hline
\end{tabular}




\begin{tabular}{|l|l|l|}
\hline \multicolumn{1}{|c|}{ Tipo da sessão } & \multicolumn{1}{|c|}{ Atividade } & \multicolumn{1}{c|}{ Palestrantes } \\
\hline Sessões paralelas 3 & Sessão 1/3 & Workshops 2 \\
\hline Sessões paralelas 3 & Sessão 2/3 & Anticorrupção 1 \\
\hline Sessões paralelas 3 & Sessão 3/3 & Alterações climáticas 1 \\
\hline Sessões paralelas 3 & Sessão 4/3 & Gênero 1 \\
\hline Sessões paralelas 3 & Sessão 5/3 & Mentalidade sustentável 1 \\
\hline Sessões paralelas 3 & Sessão 6/3 & Antipobreza 1 \\
\hline Mesa-redonda 4 & "ODS na visão dos estudantes" & $\begin{array}{l}\text { Lutz E. Schlange (PRME DACH/Suíça) } \\
\text { Giovana Chimentão Punhagui (Sistema Fiep/Brasil) } \\
\text { Kleber Marins de Paulo (Enactus/Brasil) }\end{array}$ \\
\hline Sessão plenária & $\begin{array}{l}\text { Agenda futura dos } \\
\text { ODS na educação em } \\
\text { gestão responsável }\end{array}$ & $\begin{array}{l}\text { Milenko Gudic (GT PRME Anti Pobreza/Sérvia) } \\
\text { Lutz Schlange (PRME DACH/Suíça) } \\
\text { Jonas Haertle (PRME Global/EUA) }\end{array}$ \\
\hline
\end{tabular}

Fonte: Preliminary (2017).

\section{PRINCIPAIS RESULTADOS DA $4^{\text {TH }}$ RME RESEARCH CONFERENCE}

A abertura da conferência retomou as edições anteriores da RME Research Conference, trazendo um ar de continuidade e confiança na construção dos objetivos da Agenda 2030, por meio do fomento de pesquisas relacionadas ao tema da desta. As discussões revelaram que o principal desafio que se afigura é a necessidade de fomentar o trabalho em conjunto de agentes que, embora estejam interligados pelo prisma do DS, tem enormes barreiras para o desenvolvimento do trabalho em conjunto, corroborando os desafios apontados por Laasch e Conaway (2015). Anteriormente, na Conferência Rio+20, os governos presentes receberam a notícia de que o mundo de 2012 era menos sustentável que em 1992; assim, esse foi 0 momento de definição de metas e métricas claras, com o objetivo de trazer o DS para a uma agenda pública de intervenção e cooperação entre as nações que culminaram na Agenda 2030 (United Nations, 2015).

Segundo Jeffrey Sachs, as três dimensões primordiais da agenda seriam:

- Energia: promover a transformação da matriz energética majoritariamente composta por combustíveis fósseis, como carvão, petróleo e gás natural, para um modelo de energias renováveis.

- Agricultura: fomentar tecnologias agrícolas menos nocivas ao meio ambiente, reduzindo o desmatamento e o uso de defensivos químicos e aumentando a eficiência na captação e aplicação dos recursos hídricos.

- Cidades sustentáveis: redesenhar nossas cidades para que se tornem efetivamente habitáveis. 0 ambiente urbano é repleto de desafios que impedem o cidadão do exercício da cidadania e de ter prazer em viver. Questões como poluição atmosférica, mobilidade urbana e justiça social são centrais na agenda da sustentabilidade.

Nesse contexto, a educação voltada à gestão aparece como valioso instrumento, que deve ter como uma de suas prerrogativas a interação com a sustentabilidade, tendo em vista que a temática cada vez mais é inserida no contexto globalizado do mundo corporativo. Nessa conjuntura, todo estudante de negócios deveria ter acesso a um currículo interdisciplinar, no qual estivessem presentes os conhecimentos necessários à solução dos problemas complexos de nossa sociedade. 
0 ensino da gestão deve ser pautado na lógica de que o papel dos negócios é parar de prejudicar a sociedade com práticas insustentáveis. A agenda 2030 requer que os novos gestores detenham os aspectos técnicos, políticos e éticos do DS. Dessa forma, superar o modelo de externalização do impacto socioambiental no processo produtivo e de trade-offentre lucro e DS é um desafio que se afigura para o mundo corporativo². Essa discussão confirma as dificuldades do DS apontadas na literatura e largamente discutidos por Laasch e Conaway (2015).

Portanto, os educadores da gestão têm um papel-chave na construção de um processo educativo integral, capaz de conferir a devida relevância ao valor humano e promover a prática de uma cidadania ativa e efetivamente sustentável. No entanto, existe uma necessidade latente de integração entre professores, alunos e instituições, para que a reflexão acadêmica sobre a sustentabilidade possa se traduzir em mudanças nas corporações e no estímulo de políticas públicas. Os aspectos tratados na conferência quanto à integração entre professores, alunos e instituições, bem como a discussão acerca de uma educação promotora de DS, caminharam no sentido de achados anteriores da literatura (Barth et al., 2007; Brunstein; Godoy; Silva, 2014; Gadotti, 2009; Jabbour et al., 2013; Leal Filho, 2011; Lozano-García; Kevany; Huisingh, 2006).

Entretanto, as contribuições mais inovadoras do evento, ainda pouco tratadas nas publicações sobre o tema, ficaram por conta das discussões desses aspectos à luz dos ODS. 0 foco para os ODS nos coloca diante de uma complexidade e uma interconectividade que têm que ser melhor compreendidas se desejamos alcançar as soluções até 2030. As questões de energia, agricultura e cidades evocam metas e valores numéricos que se traduzem em enormes desafios de implantação prática. É esperado que a pesquisa apresente respostas clarificadoras dessa complexidade.

Além de novas respostas, são necessárias novas perguntas. A intervenção humana na natureza precisa ser mais bem compreendida e as questões sociais podem apresentar respostas a questões que hoje são muito nebulosas. Também é necessário provocar uma interação conjunta das partes: o pesquisador deve interagir com os professores e estudantes, como também com a instituição para a concepção de programas de ensino. Desse modo, surgem as primeiras questões de pesquisa provenientes das discussões do evento:

1. Como levar esses aspectos (complexidade e multidisciplinaridade) para dentro das disciplinas e fazer que essa proposta educativa alcance as empresas? Em especial, como provocar a reflexão na liderança das empresas?

2. Como as políticas públicas podem ser estimuladas e alimentadas pelos projetos de pesquisa? Não apenas em relação à energia, à agricultura e às cidades, mas em relação às formas de se fazer política pública? Como fazer que elas funcionem efetivamente?

3. Como fazer conexões para implementar a Agenda 2030 com todos os stakeholders unidos?

Essas e outras questões emanam no palco da interação cooperativa dos agentes comprometidos com a promoção de uma sociedade justa e efetivamente sustentável, cabendo aos mesmos agentes da mudança captá-las e traduzi-las, num esforço conjunto em nível regional e global. Para Maurizio Zollo, a problemática envolvendo a falta de integração das estratégias de sustentabilidade com os stakeholders é uma das principais barreiras para a alteração do status quo e para o avanço da temática no ambiente corporativo, conforme já tratado por Bonn e Fisher (2011). Existem evidências científicas suficientes para comprovar que a sustentabilidade traz resultados, mas mesmo assim várias empresas não assumem tal compromisso. As corporações precisam ser compreendidas no âmbito de seus propósitos e objetivos econômicos, bem como nos seus processos e cultura organizacional.

2 Por externalização, entende-se a não incorporação por parte das empresas de seus possíveis impactos ambientais e sociais, advindos de suas atividades. A ideia vem da obra de 1932 de Arthur C. Pigou, The economics of welfare (2013). 0 trade-off citado refere-se à aparente contraposição entre o resultado de curto prazo de uma empresa (lucro) com a busca de DS, inerentemente voltada para o longo prazo. Esse paradoxo foi chamado de "intertemporal trade-off', por Bansal, Chapardar e Gehman (2016). 
Uma alteração no propósito de uma empresa é muito complexa; uma vez que isso ocorra é necessário checar se as conexões com os stakeholders não foram rompidas no processo. Em sua conferência, Zollo diz que, para a mudança ser efetiva, 0 aprendizado deve ocorrer no ambiente da empresa para que a corporação possa captar e absorver as aptidões necessárias ao processo de mudança, em especial no que se refere à implementação dos ODS. Isso envolve necessariamente o redesenho dos modelos de governança, com a inclusão das vozes dos stakeholders nas decisões-chave. Também é necessário integrar as estratégias para maximizar a geração de valor, direcionar os produtos/processos/modelos de pesquisa e desenvolvimento para a estratégia sustentável, além de reformular os modelos de liderança. 0 convencimento passa por um processo de evolução lógica da proteção dos riscos, bem como de resguardar os ganhos futuros.

Pelas discussões promovidas nas mesas-redondas e palestras ficou claro que as empresas têm interesse no que é debatido no mundo da pesquisa acadêmica; porém, é necessária uma mudança na proposta de valor para que exista o engajamento de fato. Essa perspectiva pode ser alcançada pela criação de uma educação em gestão flexível e dinâmica, capaz de absorver o conhecimento teórico e aplicá-lo em campo, no ambiente empresarial, na forma de estudos de caso, com o objetivo de mapear as especificidades organizacionais e propor as soluções e incentivos adequados para a mudança do status quo não sustentável. Essa educação flexível e dinâmica sugerida nas apresentações do evento já está prevista em dois princípios do PRME: diálogos e parcerias (PRME Chapter Brazil, 2017; History..., 2017).

De acordo com Isabel Rimanoczy, a ruptura desse status quo envolve o despertar da consciência de sustentabilidade que pode ser representado na metáfora da metamorfose da lagarta em borboleta. Em síntese, quando a lagarta está no limiar de sua vida, acreditando que deixou de existir, ela renasce na forma de uma nova individualidade, carregando os conhecimentos da etapa anterior. Nesse momento, a humanidade pode estar dentro de seu casulo, aguardando uma transformação que irá romper o status quo e incorporar, efetivamente, o DS como um ponto central para a continuidade da espécie humana.

O alcance dos ODS é uma questão que exigirá mais que investimentos monetários, sendo necessário também o entendimento de que a humanidade vive uma crise espiritual, considerando que o nosso estilo de vida está em ritmo acelerado (Laasch; Conaway, 2015; United Nations, 2015). A implementação da sustentabilidade passa também, necessariamente, por uma mudança do mindset e pelo surgimento de propostas disruptivas. É preciso que "a lagarta deixe de existir para dar espaço à borboleta", por isso o alinhamento com o mote da conferência, com novas perguntas que dão ensejo ao surgimento da inovação.

Todas as apresentações e palestras da $4^{\text {th }}$ RME Research Conference apontaram a necessidade da revisão do modelo de ensino da GR. Um método de ensino baseado na inter-relação das inteligências espiritual, emocional, intelectual e literária pode ser um caminho para a formação de cidadãos responsáveis, autossustentáveis, proativos e capazes de compreender e implementar a essência dos 17 ODS.

\section{CONSIDERAÇÕES FINAIS}

Apesar das iniciativas e das discussões em torno do DS e de como se portar diante desse novo fenômeno, ainda se configura como um desafio à necessidade de se formar essa nova mentalidade, principalmente para aqueles que são ou serão os responsáveis pelas organizações que se tornam críticas nesse processo. Este artigo buscou apresentar os principais elementos e diretrizes da GR como uma possível resposta a tal questão. Além disso, foram apresentados os principais elementos e experiências do PRME no Brasil e no mundo, com foco nos resultados do congresso de pesquisa do PRME, realizado no Brasil em 2017.

No escopo deste artigo, a apresentação da $4^{\text {th }}$ RME Research Conference serviu para uma ilustração prática dos temas e esforços que atualmente rumam à uma gestão/educação responsável. 0 evento promoveu um fórum para discussão em 
escala global das novas perspectivas envolvendo a implantação efetiva dos ODS e da Agenda 2030, bem como das principais questões de pesquisa que emergem nesse contexto. Além disso, o evento foi palco para a celebração do 10 aniversário do PRME e para refletir sobre os resultados alcançados e direcionar o olhar para os desafios e oportunidades futuros.

As três edições anteriores da série RME Research Conference - realizada em Chur (2014), Cairo (2015) e Krems (2016) - serviram de base para realizar a quarta edição em território brasileiro, sendo que a experiência positiva foi mantida e aprimorada. 0 evento atingiu seus objetivos de promoção do intercâmbio de conhecimento e oportunidades, na medida em que conectaram uma ampla variedade de comunidades até então pouco conectadas, sendo que ainda teve o maior público e o maior número de trabalhos e apresentações entre todas as edições ${ }^{3}$.

Estiveram presentes na organização e participação do evento os grupos de trabalho e capítulos do PRME, signatários ou não, o PNDP e o Pacto Global da ONU, bem como os principais atores regionais e o público composto por representantes de universidades, estudantes, empresas, governos, mídia e organizações da sociedade civil ansiosos para avançar seus conhecimentos e habilidades integrando a GR e o DS na formação profissional da atual e da futura geração, aqueles que são e serão 0 alicerce das organizações.

De modo geral, como conclusão, percebe-se a importância e a necessidade de uma nova forma de tratar o ambiente de negócios e, principalmente, a maneira como são e serão formados aqueles que serão os tomadores das decisões nesse ambiente. Ações como o PRME focam justamente a criação e o desenvolvimento da GR por meio da educação. Em função dos vários aspectos levantados no texto, a complexidade de tal tarefa é evidente. Nota-se também a impossibilidade de se alcançar o DS sem a participação dos vários stakeholders que, de alguma forma e em graus diferentes, influenciam a formação e a ação dos gestores. Portanto, o acesso à informação e ao conhecimento e a disseminação das melhores práticas das IES e das empresas, permitind o o compartilhamento e a troca dessas experiências, são fundamentais para o futuro das organizações, que esperamos ser mais sustentável, responsável e ético.

\section{REFERÊNCIAS}

BANSAL, Tima; CHAPARDAR, Hadi; GEHMAN, Joel. Sustainability means balancing short- and long-term priorities. MIT Sloan Management Review, Massachusetts, 17 fev, 2016. Disponível em: <https://goo.gl/raqkBP>. Acesso em: 1 mar. 2018.

BARTH, Matthias et al. Developing key competencies for sustainable development in higher education. International Journal of Sustainability in Higher Education, Bingley, v. 8, n. 4, p. 416-430, 2007.

BAUMGARTNER, Rupert J.; EBNER, Daniela. Corporate sustainability strategies: sustainability profiles and maturity levels. Sustainable Development, Hoboken, v. 18, n. 2, p. 76-89, mar./abr. 2010.

BONN, Ingrid; FISHER, Josie. Sustainability: the missing ingredient in strategy. Journal of Business Strategy, Bingley, v. 32, n. 1, p. 5-14, 2011.

BRUNSTEIN, Janette; GODOY, Arilda S.; SILVA, Helio C.C. (Orgs.) Educação para a sustentabilidade nas escolas de administração. São Carlos: RiMa, 2014.

3 A próxima edição será realizada em Colônia, Alemanha, em setembro de 2018. 
GADOTTI, Moacir. Education for sustainability: a contribution to the decade of education for sustainable development. São Paulo: Instituto Paulo Freire, 2009.

HISTORY. UNPRME.org, New York, 2018. Disponível em: <https://goo.gl/VtSteh>. Acesso em: 10 out. 2017.

JABBOUR, Charbel J. C. et al. Understanding the process of greening of Brazilian business schools. Journal of Cleaner Production, Amsterdam, v. 61, p. 25-35, dez. 2013.

JACOBI, Pedro R.; RAUFFLET, Emmanuel; ARRUDA, Michelle P. Educação para a sustentabilidade nos cursos de administração: reflexão sobre paradigmas e práticas. RAM-Revista de Administração Mackenzie, São Paulo, v. 12, n. 3, p. 21-50, maio/jun. 2011.

JONES, Paula; TRIER, Colin J.; RICHARDS, Jonathan P. Embedding education for sustainable development in higher education: a case study examining common challenges and opportunities for undergraduate programmes. International Journal of Educational Research, Amsterdam, v. 47, n. 6, p. 341-350, 2008.

LAASCH, Oliver; CONAWAY, Roger N. Principles of responsible management: global sustainability, responsibility and ethics. Boston: Cengage Learning, 2015.

LEAL FILHO, Walter. About the role of universities and their contribution to sustainable development. Higher Education Policy, New York, v. 24, n. 4, p. 427-438, dez. 2011.

LOZANO-GARCÍA, Francisco J.; KEVANY, Kathleen; HUISINGH, Donald. Sustainability in higher education: what is happening? Journal of Cleaner Production, Amsterdam, v. 14, n. 9-11, p. 757-760, 2006.

MINUZZI, Josiane; FILHO, Nelson C.; SANTOS Paulo C. F. Relações entre os valores e a liderança responsável e APLs. Revista TECAP, Pato Branco, v. 3, n. 3, p. 17-23, 2009.

ORGANIZAÇÃO DAS NAÇÕES UNIDAS PARA A EDUCAÇÃO, A CIÊNCIA E A CULTURA. Década da Educação das Nações Unidas para um Desenvolvimento Sustentável, 2005-2014: documento final do esquema internacional de implementação. Trad. de Regina Coeli Machado. Brasília: Unesco, 2005.

PIGOU, Arthur C. The economics of welfare. Basingstoke: Palgrave MacMillan, 2013.

PRELIMINARY PROGRAM. RMEConference.com, Curitiba, set. 2017. Disponível em: <https://goo.gl/9tXz33>. Acesso em: 1 mar. 2013.

PRME CHAPTER BRAZIL. Princípio 1: propósito. 2015a. Disponível em: <https://goo.gl/Z1fQd5>. Acesso em: 10 out. 2017.

PRME CHAPTER BRAZIL. Princípio 2: valores. 2015b. Disponível em: <https://goo.gl/9zSmWg>. Acesso em: 10 out. 2017.

PRME CHAPTER BRAZIL. Princípio 3: metodologia. 2015c. Disponível em: <https://goo.gl/MPNa9Z>. Acesso em: 10 out. 2017.

PRME CHAPTER BRAZIL. Princípio 4: pesquisa. 2015d. Disponível em: <https://goo.gl/dmWJ7E>. Acesso em: 10 out. 2017.

PRME CHAPTER BRAZIL. Princípio 5: parcerias. 2015e. Disponível em: <https://goo.gl/ePsPbP>. Acesso em: 10 out. 2017. 
PRME CHAPTER BRAZIL. Princípio 6: diálogo. 2015f. Disponível em: <https://goo.gl/842qnP>. Acesso em: 10 out. 2017.

SCHALTEGGER, Stefan; WAGNER, Marcus. Integrative management of sustainability performance, measurement and reporting. International Journal of Accounting, Auditing and Performance Evaluation, Olney, v. 3, n. 1, p. 1-19, 2006.

STEAD, Jean G.; STEAD, W. Edward. Sustainable strategic management: an evolutionary perspective. International Journal of Sustainable Strategic Management, Olney, v. 1, n. 1, p. 62-81, 2008.

UNITED NATIONS. Transforming our world: the 2030 agenda for sustainable development. New York: Desa-UM, 2015. Disponível em: <https://goo.gl/ImNES4>. Acesso em: 20 mar. 2017.

Texto recebido em 01/12/18 e aprovado em 20/12/17. 